\title{
Optimal supplier selection in a supply chain with predetermined loading/unloading time windows and logistics truck share
}

\author{
Alireza Fallahtafti ${ }^{1}$, Iman Ghalehkhondabi ${ }^{2}$ and Gary R. Weckman ${ }^{3}$ \\ ${ }^{1,3}$ Industrial and Systems Engineering Department, Ohio University, Athens OH 45701, USA \\ af551515@ohio.edu, weckmang @ohio.edu \\ ${ }^{2}$ School of Business and Leadership, Our Lady of the Lake University, San Antonio TX 78207, USA \\ ighalehkhonda@ollusa.edu
}

\begin{abstract}
.
Rapid population growth and increasing demand of transportation necessitate more efficient transportation and logistics processes. Efficient logistics processes in a supply chain can help the supplier selection procedure be more proficient in terms of delivery time. This paper studies a three-stage supply chain which enables truck sharing for delivery. All suppliers and the manufacturer have a time window for loading and unloading the material. A nonlinear programming model is developed to find the optimal truck share among different suppliers. A numerical example shows the applicability of the proposed model.
\end{abstract}

Keywords: Truck Sharing, Delivery Time Window, Supply Chain Management, Third Party Logistics Provider, Supplier Selection

\section{Introduction}

Supplier selection is one of the most important decision-making practices in supply chain management. Supplier selection and order assignment are two activities which affect a company's performance and its supply chain competitiveness [1]. Selecting the appropriate supplier can reduce the purchase cost and improve competency [2]. Factors such as price, quality, and delivery time would affect the supplier selection practices [3]. Increasing competency between the companies, as well as higher customer expectations, made the delivery time more important in recent years. Most companies are outsourcing their logistic processes to third-party logistics providers so they can focus more on their own specialty and competitive advantages [4].

Many researchers have studied the supplier selection problem under various assumptions and within different frameworks. Studies such as supplier selection and order assignment with supply capacity [5], logistics provider selection using analytic hierarchy process (AHP) and linear programming [6] or using fuzzy analytic network process (FANP) [7], applying multi-criteria decision making to select a third-party logistics provider [8], and selecting the third-party logistics provider for a mass customization logistics process [9] are some of the works in this area. 
Truck transportation has been a major part of logistic processes for decades. The recent increasing need for truck transportation container terminals has congestion problems even in developed ports such as the Port of Rotterdam [10]. These problems inspired researchers and decision makers to think about creative ways to encounter this truck transportation capacity problem. One of the ideas developed in order to deal with truck transportation capacity involves diving the concept of ride sharing up into logistic processes.

Ride sharing is a solution used to prevent road congestion, as well as dynamic tolling and managed lanes [11]. Ride sharing can reduce traffic congestion's negative impacts, such as air pollution and wasting resources (i.e. time, gas, etc.) [12]. In the scope of truck sharing, such concept was adopted for logistic processes. Truck sharing is a way to solve empty trips, as well as a lack of capacity issue regarding truck transportation [13]. Studies such as [14] and [15] applied the truck sharing concept in container terminals to optimize both the assignment of cranes to containers and truck sharing amongst the containers.

Although there are many research studies in the fields of truck sharing applying thirdparty logistics providers and supplier selection, no research has considered the impact of truck sharing while simultaneously selecting both the suppliers and third-party logistics providers. In this study we consider a supply chain with three stages. There is a manufacturer requiring a major raw material which can be fulfilled by different suppliers.

Third-party logistics providers are available for delivering the material from suppliers to the manufacturer. Available trucks can share capacity among the pallets from different suppliers. More explicitly, each truck can make a tour to visit different suppliers and collect pallets all in one tour to deliver to the manufacturer. According to the assumptions of ride sharing, there is a loading time window for each supplier. The manufacturer has a desired time and a possible time window for unloading the material as well. There would be a cost of opportunity if the truck couldn't be unloaded at the manufacturer's desired time. Therefore, pallets can be collected and delivered only at the time windows provided by the supplier and the manufacturer. Figure 1 shows the schematic of the studied supply chain.

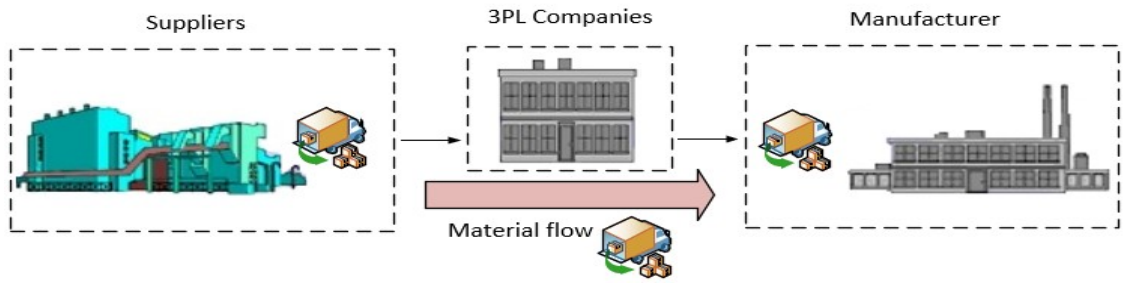

Fig. 1. Structure of proposed model

The remainder of this paper is as follows: The mathematical formulation and solution method is provided in section 2 . Section 3 is dedicated to a numerical example, and the conclusions and directions for future studies are explained in Section 4. 


\section{Mathematical Model}

We describe our network by the graph $\mathrm{G}(\mathrm{N}, \mathrm{A})$, where $\mathrm{N}$ is the set of vertices and $\mathrm{A}$ is the set of arcs. Node set $\mathrm{N}$ includes third-party logistics (3PL) providers renting load truck (D), suppliers (R) and the only manufacturer $\{0\}$ in our model. We define the first stage including the node set $\mathrm{N} 1=D \cup R$, and the second stage including node set $\mathrm{N} 2=R \cup\{0\}$. Each arc $(i, j)$ has a nonnegative cost of transportation $c t_{i j}$ based on the Euclidian distance between $\mathrm{i}$ and $\mathrm{j}$.

We apply the following assumptions and notations to our currently-studied model:

\subsection{Assumption}

- Number and location of (1) 3PL companies, (2) suppliers and (3) the manufacturer is known in advance;

- Total raw material (in pallets) demand by the manufacturer;

- It is possible that a supplier is not selected by the manufacturer (raw material can be supplied by some of the suppliers);

- A truck first visits the assigned supplier(s) and picks the raw materials up, then moves to the manufacturer's parking;

- All suppliers have a time window for loading raw material;

- A supplier (in case of selection) can be visited only by one vehicle;

- There is a limited number of parking lots and limited time for unloading raw materials;

- The Euclidean distance between $i$ and $j$ is considered as a proxy for time traveled along each arc $(i, j)$.

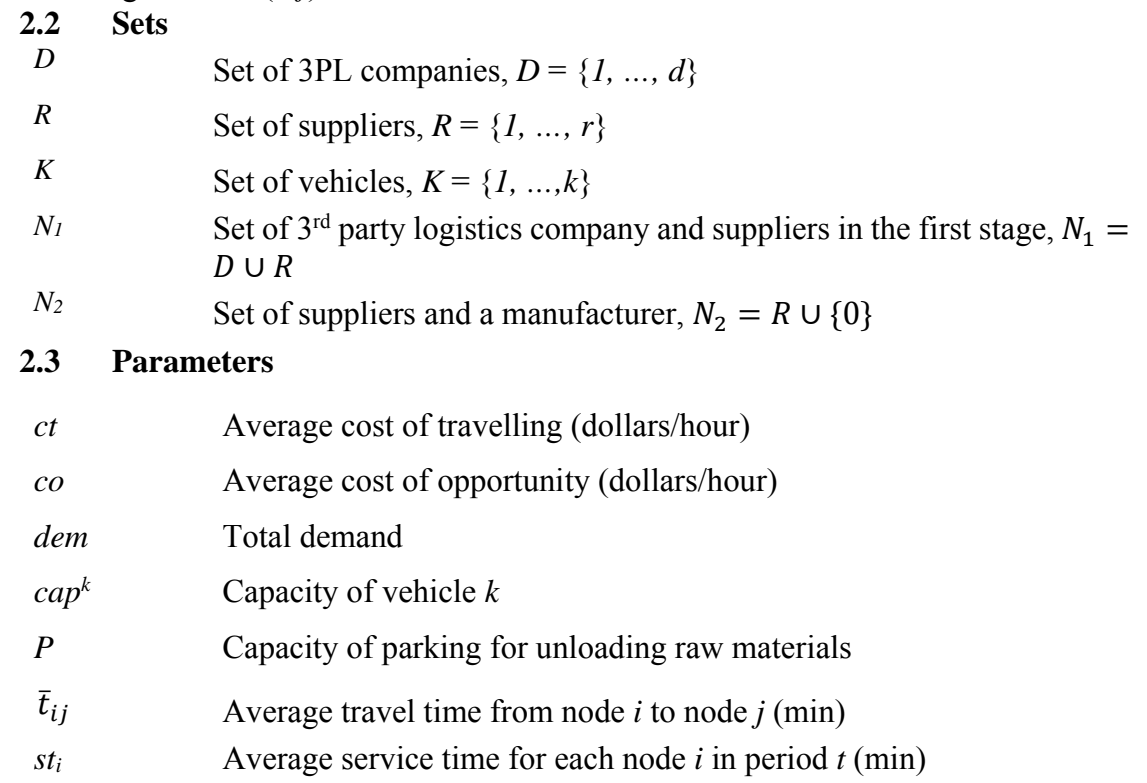


$\left[e p t_{r}, l p t_{r}\right]$ Time window constraint for supplier $r$ to deliver the raw materials

$d t u \quad$ Desired time for unloading the raw material in manufacturer's parking

Itu The latest possible time for unloading raw material in manufacturer's parking

\subsection{Decision variables}

$t_{i}^{k} \quad$ Arrival time of each vehicle to nodes $i \in N$

$x_{i j}^{k} \quad= \begin{cases}1 & \text { if vehicle } k \text { traverses arc }(i, j) \in N \\ 0 & \text { otherwise }\end{cases}$

$y_{i}^{k} \quad= \begin{cases}1 & \text { if vehicle } k \text { visit } i \in N_{2} \\ 0 & \text { otherwise }\end{cases}$

\subsection{Mathematical formulation}

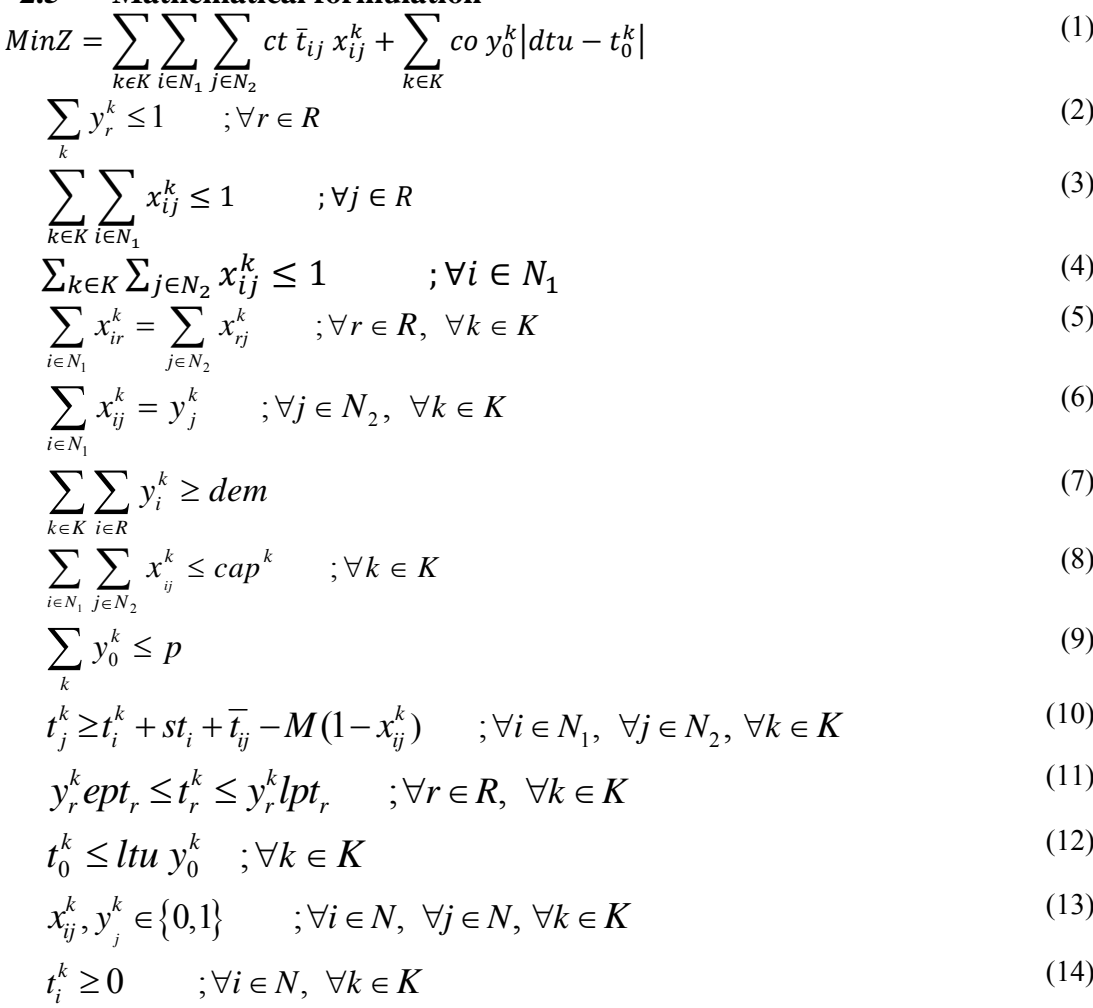

Objective function (1) minimizes the total costs including transportation cost and opportunity cost. Constraint (2) expresses that the produced raw materials and subassemblies of each supplier is picked up by at most one vehicle. Constraint (3) ensures that a truck cannot reach a certain destination from two different sources at once. Constraint (4) declares that a truck cannot head to different destinations simultaneously. Equations 
(5) and (6) are the equilibrium constraints associated to each supplier. Constraint (7) assures that the total demand should be satisfied. Constraints (8) and (9) guarantee that the truck capacity and parking capacity to unload the raw materials shipped from suppliers are respected. Constraint (10) shows the time at which each location is observed. The time window constraint of suppliers is modeled in Constraint (11) declaring that the raw materials can be picked up after the specified earliest pickup time and before the specified latest pickup time. Constraint (12) imposes that a truck should reach the parking lot for unloading the raw material before the latest possible time. Finally, constraints (13) and (14) assure the binary and non-negativity constraints on decision variables.

\subsection{Model linearization}

The proposed model in this study is a mixed integer nonlinear program (MINLP). However, we can rewrite the objective function in the linear format using a set of linear constraints [16]. Linearizing the objective function (1):

$$
\begin{aligned}
\text { MinZ } & =\sum_{k \in K} \sum_{i \in N_{1}} \sum_{j \in N_{2}} c t \bar{t}_{i j} x_{i j}^{k}+\sum_{k \in K} \cos y_{0}^{k}\left|d t u-t_{0}^{k}\right| \\
& =\sum_{k \in K} \sum_{i \in N_{1}} \sum_{j \in N_{2}} c t \bar{t}_{i j} x_{i j}^{k}+\sum_{k \in K} \cos y_{0}^{k}\left(\alpha_{1}^{k}+\alpha_{2}^{k}\right) \\
\alpha_{1}^{k}-\alpha_{2}^{k}=d t u-t_{0}^{k} ; \forall k & ; \alpha_{1}^{k}, \alpha_{2}^{k} \geq 0
\end{aligned}
$$

Objective function (16) is still nonlinear. Each of two expressions in the objective function should be rewritten again. The following formulas show the linearized form of $\sum_{k \in K} \cos y_{0}^{k} \alpha_{1}^{k}$ :

$$
\begin{aligned}
& \sum_{k \in K} \operatorname{coy}_{0}^{k} \alpha_{1}^{k}=\sum_{k \in K} \operatorname{co}_{1 a}^{k} \\
& \alpha_{1 a}^{k} \leq M y_{0}^{k} \quad ; \forall k \\
& \alpha_{1 a}^{k} \leq \alpha_{1}^{k} \quad ; \forall k \\
& \alpha_{1 a}^{k} \geq \alpha_{1}^{k}-M\left(1-y_{0}^{k}\right) \quad ; \forall k
\end{aligned}
$$

Constraints (17), (18), (20), (21), and (22) are the new constraints of our optimization model. $\sum_{k \in K} \operatorname{coy}_{0}^{k} \alpha_{2}^{k}$ in equation (16) should be rewritten in a same manner as (19) to (22).

\section{Computational results}

To demonstrate the applicability of the proposed model, a numerical example is conducted in this section. Consider a supply chain with 8 suppliers and a manufacturer. The manufacturer requires 5 pallets of raw material in order to run its production process. All the suppliers can provide one pallet of raw material, but the manufacturer can choose the suppliers based upon the travelling and opportunity costs. There are three third-party logistics providers (3PLs) with one truck each. Additionally, 3PLs can apply ride sharing in order to reduce the shipment cost. Travel cost is obtained based on the 
Euclidian distance, and is provided in table 1. Other required parameter values are provided in tables 2 and 3.

Table 1. Travel time between nodes (minutes)

\begin{tabular}{|c|c|c|c|c|c|c|c|c|c|c|c|c|}
\hline & parking & $\mathrm{d}_{1}$ & $\mathrm{~d}_{2}$ & $\mathrm{~d}_{3}$ & $\mathrm{r}_{1}$ & $\mathrm{r}_{2}$ & $r_{3}$ & $r_{4}$ & $\mathrm{r}_{5}$ & $\mathrm{r}_{6}$ & $\mathrm{r}_{7}$ & $\mathrm{r}_{8}$ \\
\hline Parking & 0 & 27 & 40 & 40 & 42 & 38 & 48 & 30 & 42 & 42 & 38 & 42 \\
\hline $\mathrm{d}_{1}$ & & 0 & 48 & 67 & 19 & 27 & 40 & 30 & 57 & 57 & 60 & 68 \\
\hline $\mathrm{d}_{2}$ & & & 0 & 57 & 48 & 72 & 27 & 19 & 81 & 13 & 30 & 48 \\
\hline$d_{3}$ & & & & 0 & 81 & 72 & 78 & 60 & 48 & 48 & 30 & 13 \\
\hline $\mathrm{r}_{1}$ & & & & & 0 & 42 & 30 & 30 & 75 & 60 & 68 & 80 \\
\hline $\mathrm{r}_{2}$ & & & & & & 0 & 67 & 55 & 42 & 78 & 75 & 78 \\
\hline$r_{3}$ & & & & & & & 0 & 19 & 89 & 40 & 55 & 72 \\
\hline $\mathrm{r}_{4}$ & & & & & & & & 0 & 72 & 30 & 40 & 55 \\
\hline$r_{5}$ & & & & & & & & & 0 & 80 & 68 & 60 \\
\hline $\mathrm{r}_{6}$ & & & & & & & & & & 0 & 19 & 38 \\
\hline $\mathrm{r}_{7}$ & & & & & & & & & & & 0 & 19 \\
\hline $\mathrm{r}_{8}$ & & & & & & & & & & & & 0 \\
\hline
\end{tabular}

Table 2. Parameters

\begin{tabular}{lrll}
\hline parameter & value & \multicolumn{1}{c}{ parameter } & value \\
\hline$d e m$ & 5 & $d t u$ & $3 \mathrm{pm}$ \\
$c t$ & 40 & $l t u$ & $5 \mathrm{pm}$ \\
$c o$ & 30 & cap $^{k 1}$ & 3 \\
$P$ & 3 & cap $^{k 2}$ & 2 \\
$s t_{i}$ & 30 & cap $^{k 3}$ & 1 \\
\hline
\end{tabular}

Table 3. Suppliers' loading time window

\begin{tabular}{llllllll}
\hline$r_{1}$ & $r_{2}$ & $r_{3}$ & $r_{4}$ & $r_{5}$ & $r_{6}$ & $r_{7}$ & $r_{8}$ \\
\hline$[10 \mathrm{am}, 11 \mathrm{am}]$ & {$[10 \mathrm{am}, 12 \mathrm{pm}]$} & {$[11 \mathrm{am}, 12 \mathrm{pm}]$} & {$[9 \mathrm{am}, 10 \mathrm{am}]$} & {$[10 \mathrm{am}, 11 \mathrm{am}]$} & {$[10 \mathrm{am}, 12 \mathrm{pm}]$} & {$[11 \mathrm{am}, 12 \mathrm{pm}]$} & {$[12 \mathrm{pm}, 1 \mathrm{pm}]$} \\
\hline
\end{tabular}

Solving the model gives us the lowest possible cost of $\$ 204$, which would be achievable through the following schedule:

- The truck from the 1st logistics company takes one pallet from the first supplier at $10 \mathrm{am}$, one pallet from the fourth supplier at $12 \mathrm{pm}$, and unloads the entire shipment in the manufacturer's parking lot at $3 \mathrm{pm}$.

- The truck from the 2nd logistics company takes one pallet from the sixth supplier at $10 \mathrm{am}$, one pallet from the seventh supplier at $11 \mathrm{am}$, and unloads the entire shipment in the manufacturer's parking lot at $3 \mathrm{pm}$.

- The truck from the 3rd logistics company takes one pallet from the 8th supplier at $12 \mathrm{pm}$ and unload the entire shipment in the manufacturer's parking lot at 3 $\mathrm{pm}$. 
Figure $r$ shows the solution schematically.
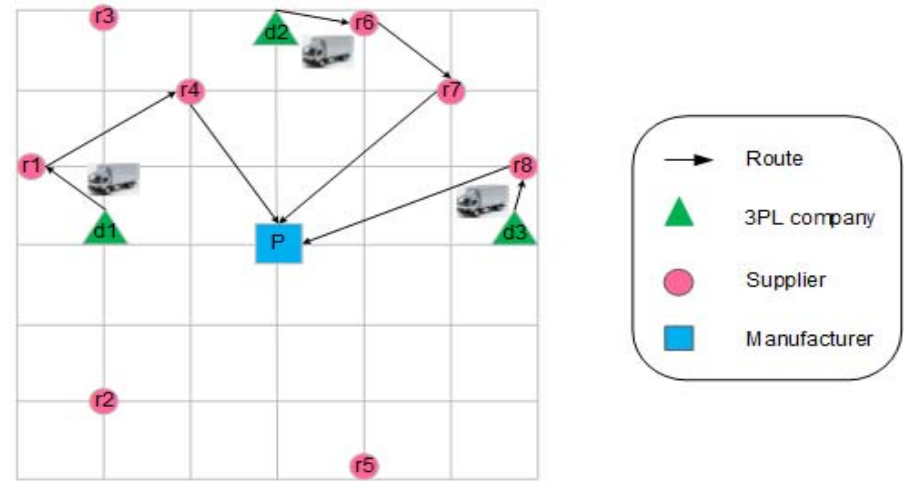

Fig. 2. Optimal truck share plan

The short distance between different suppliers and the manufacturer's parking makes it possible to deliver the material to the manufacturer earlier than the specified time, but the manufacturer's employees would only be available at the assigned time slot from 3 $\mathrm{pm}$ to $5 \mathrm{pm}$. This solution shows the possibility of an agreement between the suppliers and the manufacturer to coordinate on loading/unloading time windows.

\section{Conclusions}

The truck transportation sector has witnessed a demand boom in recent years. Sharing trucks among different loads can optimize the truck capacity utilization and reduce traffic congestion as well. Improved transportation services would increase the competitiveness of third-party logistics providers. The proposed model in this study showed the applicability of truck sharing in a three-stage supply chain. Numerical example results show that the available trucks can be shared among the suppliers in order to deliver material to the manufacturer while still considering the available time windows for loading/unloading trucks. Studying the same problem in a multi-objective framework would be an interesting topic for future research. Moreover, considering uncertain time windows and traveling times may increase the attractiveness of the model. Studying the possibility of bargaining on the loading/unloading time windows amongst the chain players would be a valuable area for future research, as well.

\section{References}

[1] K. S. Moghaddam, "Fuzzy multi-objective model for supplier selection and order allocation in reverse logistics systems under supply and demand uncertainty," $E x$ pert Systems with Applications, vol. 42, no. 15-16, pp. 6237-6254, 2015. 
[2] T. H. Willis, C. R. Huston, and F. Pohlkamp, "Evaluation measures of just-in-time supplier performance," Production and Inventory Management Journal, vol. 34, no. 2, p. 1, 1993.

[3] D. L. Moore and H. E. Fearon, "Computer-Assisted Decision-Making in Purchasing," Journal of Purchasing, vol. 9, no. 4, pp. 5-25, 1973.

[4] G. Vaidyanathan, "A framework for evaluating third-party logistics," Communications of the ACM, vol. 48, no. 1, pp. 89-94, 2005.

[5] S. H. Ghodsypour and C. O'brien, "The total cost of logistics in supplier selection, under conditions of multiple sourcing, multiple criteria and capacity constraint," International journal of production economics, vol. 73, no. 1, pp. 15-27, 2001.

[6] Y. Tian, K. Zantow, and C. Fan, "A framework of supplier selection of integrative logistics providers," International Journal of Management and Enterprise Development, vol. 7, no. 2, pp. 200-214, 2009.

[7] M. N. Nobar, M. Setak, and A. F. Tafti, "Selecting suppliers considering features of 2nd layer suppliers by utilizing FANP procedure," International Journal of Business and Management, vol. 6, no. 2, p. 265, 2011.

[8] B.-N. Hwang and Y.-C. Shen, "Decision making for third party logistics supplier selection in semiconductor manufacturing industry: a nonadditive fuzzy integral approach," Mathematical Problems in Engineering, vol. 2015, 2015.

[9] X. Hu, G. Wang, X. Li, Y. Zhang, S. Feng, and A. Yang, "Joint decision model of supplier selection and order allocation for the mass customization of logistics services," Transportation Research Part E: Logistics and Transportation Review, vol. 120, pp. 76-95, 2018.

[10] B. Behdani, Y. Fan, B. Wiegmans, and R. Zuidwijk, "Multimodal schedule design for synchromodal freight transport systems," Behdani, B., Fan, Y., Wiegmans, B., \& Zuidwijk, pp. 424-444, 2014.

[11] C. Xiong, P. Hetrakul, and L. Zhang, "On ride-sharing: a departure time choice analysis with latent carpooling preference," Journal of Transportation Engineering, vol. 140, no. 8, p. 04014033, 2014.

[12] F.-Y. Wang, S. Tang, Y. Sui, and X. Wang, "Toward intelligent transportation systems for the 2008 Olympics," IEEE Intelligent Systems, vol. 18, no. 6, pp. 8$11,2003$.

[13] S. Islam and T. Olsen, "Truck-sharing challenges for hinterland trucking companies: a case of the empty container truck trips problem," Business Process Management Journal, vol. 20, no. 2, pp. 290-334, 2014.

[14] S. Islam, "Simulation of truck arrival process at a seaport: evaluating truck-sharing benefits for empty trips reduction," International Journal of Logistics Research and Applications, vol. 21, no. 1, pp. 94-112, 2018.

[15] B. Vahdani, F. Mansour, M. Soltani, and D. Veysmoradi, "Bi-objective optimization for integrating quay crane and internal truck assignment with challenges of trucks sharing," Knowledge-Based Systems, vol. 163, pp. 675-692, 2019.

[16] M. S. Bazaraa, J. J. Jarvis, and H. D. Sherali, Linear programming and network flows. John Wiley \& Sons, 2011. 